\title{
IMAGEN 8-2012: PRUEBA TERAPÉUTICA CON NEOSTIGMINA EN PACIENTE GON MIASTENIA GRAVIS.
}
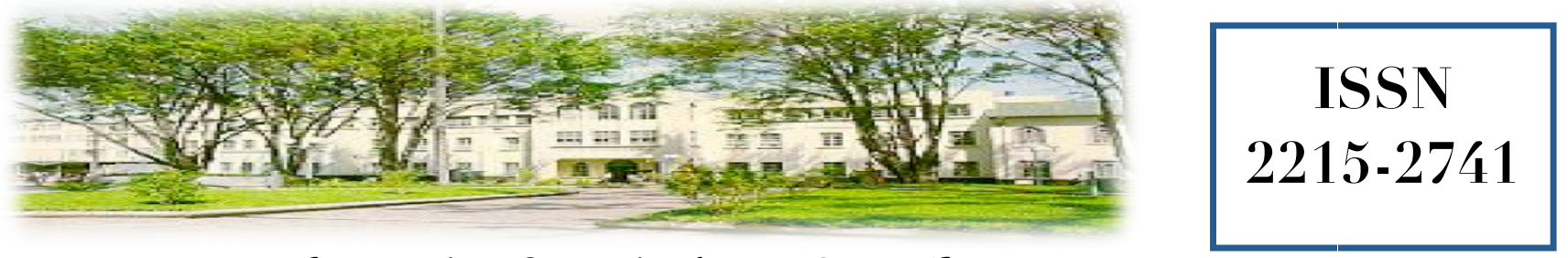

Haspital San Juan de Dias. San José, Costa Riva. Fundada en 1845

Recibido: $\quad 10 / 08 / 2012$

Aceptado: $\quad 22 / 08 / 2012$

Freddy Henríquez Varela ${ }^{1}$

${ }^{1}$ Especialista en Medicina Interna y Neurología. Asistente del Servicio de Neurología, Hospital San Juan de Dios. Profesor Escuela de Medicina de la U.C.R. Correo electrónico: henriquez@medicos.cr

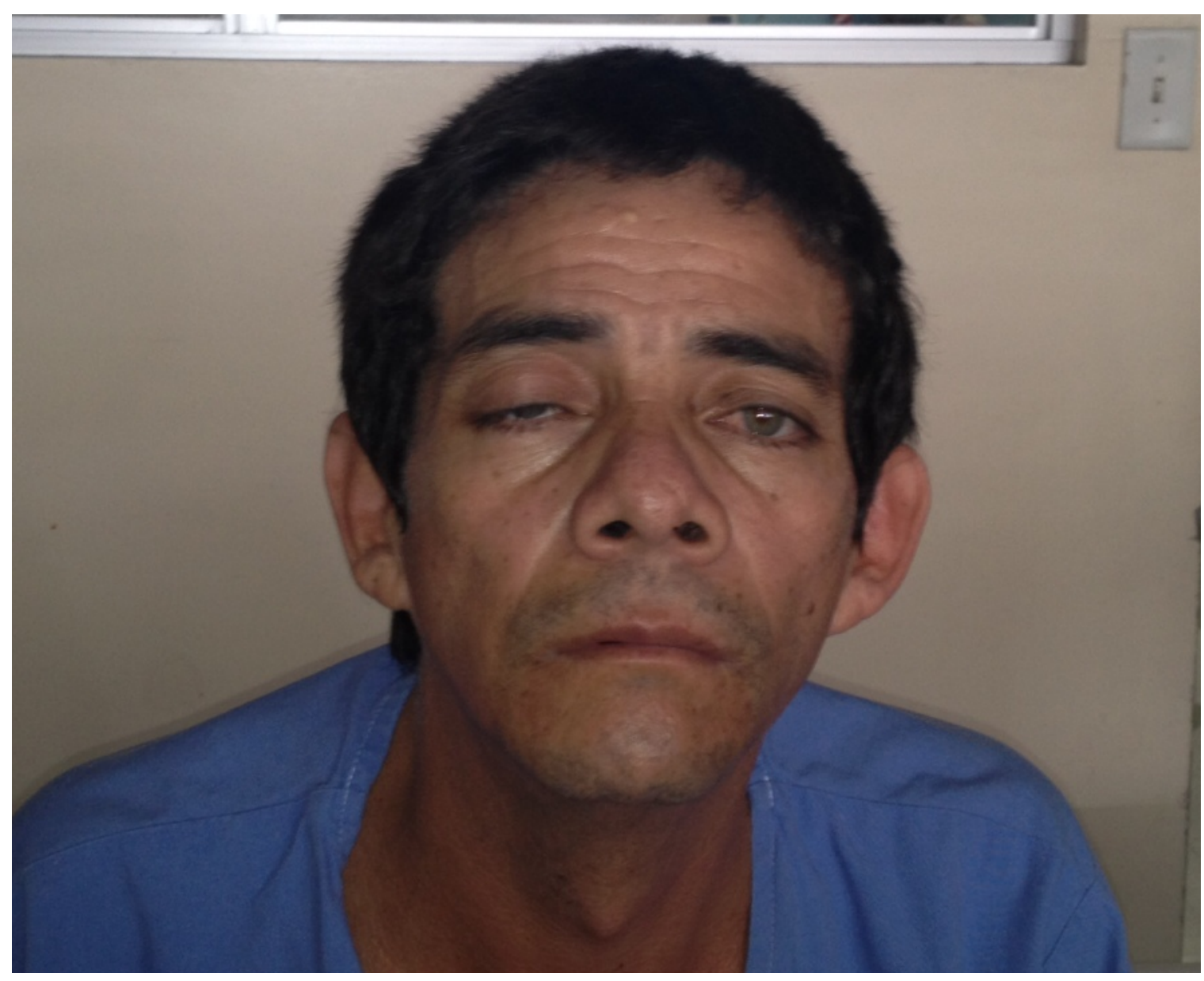




\section{CARACTERIZACIÓN DEL CASO}

Paciente masculino 45 años, con cuadro subagudo caracterizado por diplopía y ptosis palpebral, de evolución subaguda, por lo que consulta al servicio de emergencias de nuestro hospital.

Figura 1. Ptosis palpebral predominio derecho, previo a tratamiento

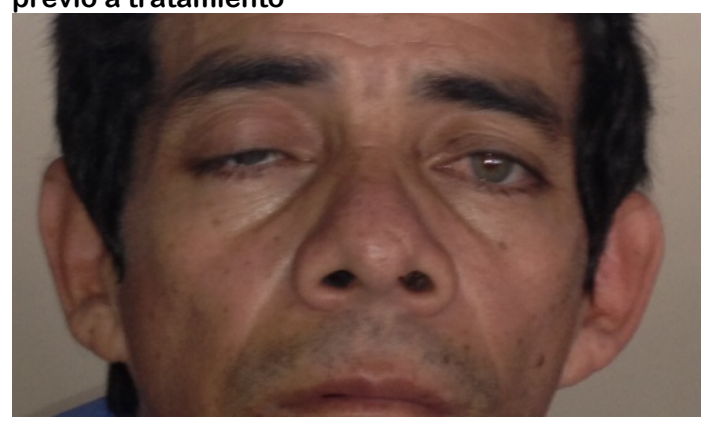

Fuente propia con autorización.

Figura 2. Luego de prueba con neostigmina

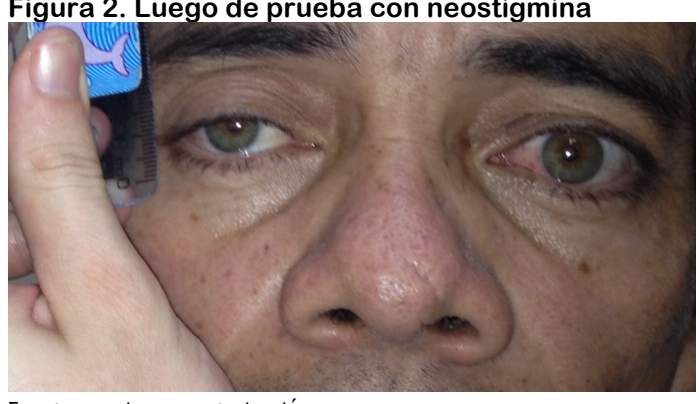

Fuente propia con autorización.

\section{DISCUSIÓN}

La miastenia gravis es una enfermedad autoinmune cuyo signo clínico pivote es la fatigabilidad. Una de los síntomas mayores es la debilidad ocular, manifestada por oftalmoparesia o ptosis palpebral. Su frecuencia en Estados Unidos de América es de 20 casos por cada 100.000 habitantes $^{(1)}$ y debido a las potenciales complicaciones, el diagnóstico debe ser hecho con prontitud.

En 1941 Harvey y Lilienthal publicaron el uso diagnóstico de la neostigmina por primera $\mathrm{vez}^{(2)}$. En 1953, Hutchinson y Matthews confirmaron esa teoría, ambos estudios, utilizaron inyecciones intraarteriales, a nivel braquial ${ }^{(3)}$.

El edrofonio se utilizó históricamente como prueba diagnóstica, sin embargo, la escasa producción y distribución han llevado este ensayo al desuso, volviendo la neostigmina a ser importante en las pruebas diagnósticas.

La sensibilidad de la prueba de neostigmina es de $96 \%$ para las presentaciones generalizadas y entre el 69 y $91 \%$ para la miastenia ocular ${ }^{(4)}$.

\section{La prueba}

1. Suspender agentes con efecto anticolinesterasa, al menos 8 horas antes de la prueba ${ }^{(5)}$.

2. Administrar atropina, a una dosis de 0,5 mg IM 30 minutos antes de la administración de la neostigmina ${ }^{(5)}$.

3. Aplicar neostigmina IM y valorar respuesta durante los próximos 30 minutos.

4. Valorar la fuerza muscular facial y de las 4 extremidades. La disminución de la ptosis en más de $2 \mathrm{~mm}$ también es criterio de mejoría significativa.

Con esta prueba, cabe la posibilidad de que pacientes con miopatía mejoren en algo la fuerza muscular, pero sólo los miasténicos tendrán una mejoría significativa.

\section{BIBLIOGRAFÍA}

1. Phillips LH $2^{\text {nd }}$. The epidemiology of myasthenia gravis. Ann N Y Acad Sci 2003; 998:407-412.

2. Harvey AM Lilienthal J L Jr. 1941 Bull: Intraarterial Neostigmine Test. John Hopk Hosp 69;566.

3. Hutchinson EC Matthews WB. The intraarterial injection of neostigmine as a diagnostic test in myasthenia gravis. $\mathrm{J}$. Neurol. Neurosurg. Psychiat. 1953;16:47-48.

4. Beekman R Kuks JB Oosterhuis HJ. Myasthenia gravis: diagnosis and follow-up of 100 consecutive patients. J Neurol 1997;244:112-118.

5. McEvoy GK. Neostigmine bromide, neostigmine methylsulfate. Bethesda, MD: American Society of Health-System Pharmacists; 2007:1245-1247. 